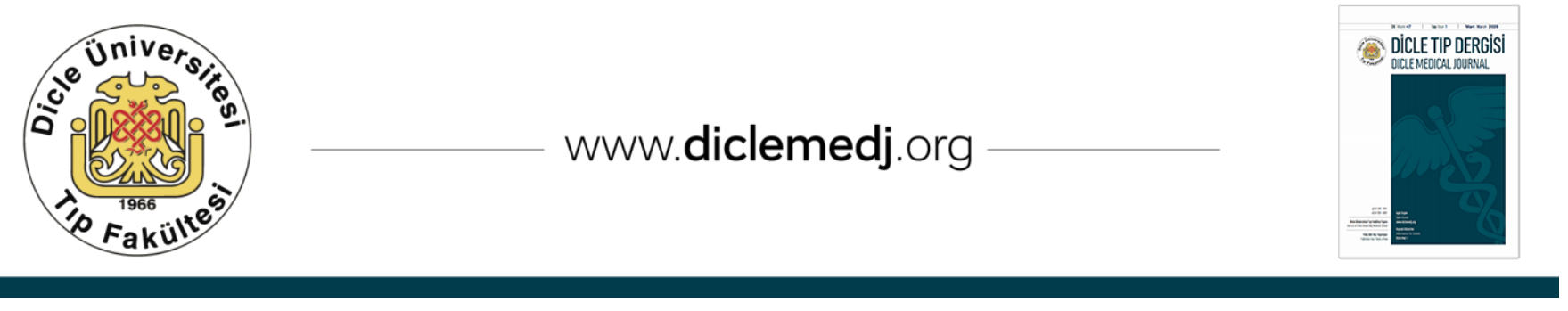

\title{
Soliter Pulmoner Nodüllerin Değerlendirilmesi: Malign Lezyonların Ayırıcı Tanısında F-18 FDG PET/BT' Nin Tanısal Değeri
}

\author{
Sibel Uçak Semirgin¹ ${ }^{\text {iD }, ~ N i l u ̈ f e r ~ B ı c ̧ a k c ̧ ı ² ~ i D ~}$ \\ 1 Ondokuz Mayıs Üniversitesi Tıp Fakültesi, Nükleer Tıp Anabilim Dalı, Samsun, Türkiye \\ 2 SBÜ, Samsun Eğitim ve Araștırma Hastanesi, Nükleer Tıp Bölümü, Samsun, Türkiye \\ Geliș: 06.11.2019; Revizyon: 06.02.2020; Kabul Tarihi: 11.02.2020
}

$\ddot{0} \mathbf{z}$

Amaç: Soliter pulmoner nodüllerde tedavi yaklaşımının doğru şekilde belirlenmesi açısından malign - benign lezyon ayırıcı tanısının yapılması oldukça önemlidir. Flor-18 florodeoksiglukoz (F-18 FDG) PET/BT, morfolojik ve metabolik bilgiyi bir arada sunarak lezyon karakterizasyonuna önemli katkı sağlayan bir görüntüleme yöntemidir. Çalışmamızda, soliter pulmoner nodüllerde F-18 FDG PET/BT yönteminin malign lezyon ayırıcı tanısına katkısının araştırılması amaçlanmıştır.

Yöntemler: Bilgisayarlı tomografide maksimum aksiyel çapı 1-3 $\mathrm{cm}$ arasında soliter pulmoner nodül saptanan, nodül karakterizasyonu amacı ile F-18 FDG PET/BT tetkiki uygulanan 54 hastaya ait bulgular retrospektif olarak değerlendirildi. Tüm hastaların histopatolojik tanıları mevcuttu. Nodüllerin maksimum aksiyel çapları ve maksimum standardize tutulum değerleri (maksSTD) belirlenerek histopatolojik son tanılar ile karşılaştırıldı. MaksSTD için 2,5 eşik değer olarak kabul edildiğinde (benign $<2,5$ ve malign $\geq 2,5$ ) lezyonlardaki bulgular değerlendirildi ve F-18 FDG PET/BT tetkikinin malign lezyon tespitindeki tanısal değeri araştırıldı.

Bulgular: Çalışmaya dahil edilen 54 hastanın (42 erkek, 12 kadın) yaş ortalaması ( \pm ss) $61 \pm 11$ idi. Histopatolojik olarak 38 hastada malign $(\% 70,4), 16$ hastada benign $(\% 29,6)$ bulgular saptandı. Malign lezyon saptanan hastalarda en sık tanı adenokarsinom (14/38 hasta, \%36,8), benign lezyon saptananlarda ise sirasiyla kronik nonspesifik inflamasyon $(7 / 16$ hasta, \%43,8) ve nekrotizan granülomatöz inflamasyon (6/16 hasta,\%37,5) olarak belirlendi. MaksSTD eşik değerinin altında tutulum izlenen malign lezyon tanılı hastaların birisinde skuamöz hücreli karsinom ve diğerinde karsinoid tümör tespit edildi. Benign lezyon tanısı olan 8/16 hastada $(\% 50,0)$ maksSTD eşik değerin üzerinde idi; bu hastaların 4' ünde kronik nonspesifik inflamasyon, 3'ünde nekrotizan granülomatöz inflamasyon ve 1'inde aspergilloz mevcuttu. Benign ve malign lezyonların medyan aksiyel çapları arasında istatistiksel olarak anlamlı fark izlenmezken, maksSTD değerleri malign lezyonlarda anlamlı düzeyde yüksek bulundu ( $p=0,001)$. MaksSTD için eşik değer 2,5 olarak kabul edildiğinde malign lezyonların tespitinde F-18 FDG PET-BT tetkikinin duyarlılı̆̆ı \%95,1 ve özgüllüğü \%50,0 olarak belirlendi.

DOI: 10.5798/dicletip.706135

Yazışma Adresi / Correspondence: Sibel Uçak Semirgin, Ondokuz Mayıs Üniversitesi Tıp Fakültesi Hastanesi, Nükleer Tıp Anabilim Dall, 0. Kat Kurupelit/Samsun, Türkiye e-mail: sibelucak@yahoo.com 
Sonuç: Çalışmamızdan elde edilen veriler, F-18 FDG PET/BT' nin aksiyel çapı 1 cm'den büyük soliter pulmoner nodüllerde benign-malign lezyon ayrımı için yüksek duyarlılığa sahip bir görüntüleme yöntemi olduğu yönündedir. Tetkikin özgüllüğü göreceli düşüktür. En sık yanlış pozitif bulgu veren durumlar kronik inflamasyonlar ve granülomatöz lezyonlardır. Ülkemizde halen sıklıkla karşılaşılması nedeni ile özellikle tüberküloz enfeksiyonu açısından ayırıcı tanı için hastaların klinik bulgularına özellikle dikkat edilmesi gerekmektedir. Düşük grade'li bazı malign lezyonlarda da tetkikin yanlış negatif sonuçlar verebileceği göz önünde bulundurulmalıdır.

Anahtar kelimeler: Pulmoner nodül, FDG, PET/BT, tüberküloz

\title{
Evaluation Of Solitary Pulmonary Nodules: Diagnostic Value Of F-18 FDG PET/CT In The Differential Diagnosis Of Malignant Lesions
}

\begin{abstract}
Objective: The differential diagnosis of malign and benign lesions is very important for the accurate determination of the treatment approach in solitary pulmonary nodules. Fluorine-18 fluorodeoxyglucose (F-18 FDG) PET/CT is an imaging method that provides significant contribution to lesion characterization by providing morphological and metabolic information together. In our study, we aimed to research the contribution of F-18 FDG PET/CT to the differential diagnosis of malignant lesions in solitary pulmonary nodules.

Methods: Fifty-four patients who had solitary pulmonary nodule with maximal axial diameter of 1-3 cm on computed tomography and underwent F-18 FDG PET/CT for nodule characterization were retrospectively evaluated. All patients had histopathological diagnosis. Maximum axial diameters and maximum standardized uptake values (maxSUV) of nodules were determined and compared with histopathological diagnoses. Assuming a threshold of 2.5 for maxSUV (benign $<2.5$ and malignant $\geq 2.5$ ), the findings of lesions were evaluated and the diagnostic value of F-18 FDG PET/CT in the detection of malignant lesions was researched. Results: The mean age of 54 patients included in the study (42 males, 12 females) was ( \pm sd) $61 \pm 11$ years. Malign and benign histopathological findings were detected in 38/54 (70.4\%) and 16/54 (29.6\%) patients respectively. The most common diagnoses in patients with malignant lesions were adenocarcinoma (14/38 patients, $36.8 \%)$ and in patients with benign lesions chronic nonspecific inflammation $(7 / 16$ patients, $43.8 \%$ ) and necrotizing granulomatous inflammation (6/16 patients, 37.5\%). In two patients with malignancy, maxSUV was below the threshold value; one patient had squamous cell carcinoma and the other had carcinoid tumor. In 8/16 patients (50.0\%) diagnosed with benign lesions, the maxSUV was above the threshold; 4 of these patients had chronic nonspecific inflammation, 3 had necrotizing granulomatous inflammation and 1 had aspergillosis. There was no statistically significant difference between the median axial diameters of benign and malignant lesions, whereas maxSUV were significantly higher in malignant lesions $(\mathrm{p}=0.001)$. If the threshold value for maxSUV was accepted as 2.5 , the sensitivity and specificity of F-18 FDG PET/CT were95.1\% and 50.0\% respectively, in the detection of malignant lesions.

Conclusion: The data obtained from our study suggest that F-18 FDG PET/CT is a high-sensitivity imaging method for the differential diagnosis of solitary pulmonary nodules with an axial diameter of greater than $1 \mathrm{~cm}$. The specificity is relatively low. The most common false positive findings are chronic inflammations and granulomatous lesions. Due to the fact that tuberculosis infection is still frequently encountered in our country, it is necessary to pay special attention to the clinical findings of the patients for differential diagnosis. In some low grade lesions, it should be taken into consideration that F-18 FDG PET/CT may give false negative results.
\end{abstract}

Keywords: Pulmonary nodule, FDG, PET/CT, tuberculosis.

\section{GİRiş}

Flor-18 florodeoksiglukoz (F-18 FDG) PET/BT, birçok kanser türünde olduğu gibi akciğer kanserlerinin de ayırıcı tanısında yaygın olarak kullanılan bir görüntüleme yöntemidir. F-18
FDG PET/BT yöntemi, lezyonlara ilişkin morfolojik ve metabolik bilgiyi bir arada sunmakta ve görsel değerlendirmenin yanı sıra maksimum standardize tutulum değeri (maksSTD) hesabı ile semikantitatif 
değerlendirmeyi de mümkün kılmaktadır ${ }^{1}$. Soliter pulmoner nodüller (SPN) büyük oranda tesadüfi olarak saptanan lezyonlardır. Özellikle yüksek çözünürlüğe sahip bilgisayarlı tomografi sistemlerinin kullanımının yaygınlaşmasına paralel olarak, semptomsuz hastalarda akciğer nodüllerinin tespitinde de artış olduğu görülmektedir. Malign akciğer lezyonu tespit edilen hastalarda erken tanının sağ kalım oranlarında önemli artış sağladığı bilinmektedir. Bu nedenle SPN tanılı hastalarda malign lezyon ayırıcı tanısının yapılması oldukça önemlidir. Birçok benign akciğer lezyonu direk grafide SPN görünümüne neden olmakla birlikte, özellikle erken evre akciğer kanserlerinde ve metastatik lezyonlarda da benzer bulgular izlenebilmektedir. Radyolojik olarak malign ve benign lezyon ayırıcı tanısı için bazı kriterler tanımlanmıştır ancak bu kriterlerin zaman zaman yanıltıcı olabileceği de bildirilmiştir $^{2}$. F-18 FDG PET/BT yöntemi füzyon görüntüler sayesinde morfolojik ve metabolik bilgiyi bir arada sunarak lezyon karakterizasyonuna önemli katkı sağlayan bir görüntüleme yöntemidir. Soliter pulmoner nodül tanısında ve takibinde de yüksek duyarlılık ve özgüllüğe sahip olduğu yönünde çok sayıda çalışma bulunmaktadır ${ }^{3}$. Çalışmamızda, SPN' lerde F-18 FDG PET/BT yönteminin malign lezyon ayırıcı tanısına katkısının araştırılması amaçlanmıştır.

\section{YÖNTEMLER}

Bilinen malignite tanısı olmaksızın bilgisayarlı tomografide maksimum aksiyel çapı $1-3 \mathrm{~cm}$ arasında pulmoner nodüler lezyon saptanan, nodül karakterizasyonu amacı ile Kasım 2017 Mayıs 2019 tarihleri arasında F-18 FDG PET-BT tetkiki uygulanan ve histopatolojik son tanıları mevcut olan 54 hasta retrospektif olarak değerlendirildi. Çalışma Ondokuz Mayıs Üniversitesi Klinik Araştırmalar Etik Kurulu tarafından onaylandı. PET/BT görüntüleri GE Discovery IQ PET/BT ve Philips Gemini TF Time of Flight (TOF) PET / BT cihazları ile elde edildi.
En az 6 saatlik açlığı takiben 1 lt su içerisinde noniyonik kontrast madde oral olarak hastalara verildi. Radyofarmasötik enjeksiyonu öncesi tüm hastaların kan glikoz düzeyleri ölçülerek, değeri $150 \mathrm{mg} / \mathrm{dL}$ 'nin altında olan hastalara 0,15- 0,20 $\mathrm{mCi} / \mathrm{kg}$ dozunda F-18 FDG intravenöz olarak uygulandı. Enjeksiyondan 4560 dakika sonra supin pozisyonda kafa tabanı üst uyluk bölgesini içerecek şekilde PET/BT görüntüleri elde edildi. PET görüntüleri her bir yatak pozisyonu için 2 dakika olacak şekilde ve 3,3 mm rekonstrüksiyon kesit kalınlığında alındı. Füzyon BT görüntüleri $3,8 \mathrm{~mm}$ rekonstrüksiyon kesit kalınlığında, $120 \mathrm{kV}$ ve 150-295 mA parametreleri ile elde edildi. Görüntüler transvers, koronal ve sagital kesitlerde görsel olarak ve maksimum standardize tutulum değerleri hesaplanarak (maksSTD) semi kantitatif olarak değerlendirildi. Füzyon BT görüntüleri üzerinden lezyonların maksimum aksiyel çapları hesaplandı. Lezyonların maksimum aksiyel çapları ve maksSTD histopatolojik son tanılar ile karşılaştırıldı. MaksSTD için eşik 2,5 olarak kabul edildiğinde malign ve benign lezyon ayrımında F-18 FDG PET/BT tetkikinin tanısal değeri araştırıldı.

Verilerin normal dağılıma uygunluğu Kolmogorov-Smirnov testi ile değerlendirildi. Verilerin karşılaştırılmasında kategorik ölçümler için Ki Kare testi, sürekli ölçümler için Mann Whitney U testi kullanıldı. Tüm testlerde istatistiksel önemin eşik değeri olarak 0,05 düzeyi baz alındı. Verilerin istatistiksel analizi SPSS 21.0 paket programı ile yapıldı.

\section{BULGULAR}

Çalışmaya dahil edilen 54 hastanın (42 erkek,


ortanca yaş (min-maks) 65 (37-83) yll idi. Patoloji materyalleri 30 hastada $(\% 55,6)$ transbronşiyel biyopsi ile, 10 hastada $(\%$ 18,5) transtorasik biyopsi ile ve 14 hastada $(\% 25,9)$ transtorasik rezeksiyon ile elde edildi. 
Histopatolojik olarak 38 hastada malign $(\% 70,4), 16$ hastada benign $(\% 29,6)$ bulgular saptand. Malign ve benign lezyon saptanan hasta sayıları ve histopatolojik bulgular tablo I' de verilmiştir.

Tablo I: Malign ve benign lezyon saptanan hasta saylları ve histopatolojik bulgular.

\begin{tabular}{|lc|}
\hline Histopatolojik Tanı & Hasta Sayısı \\
\hline Malign & $38(\% 70,4)$ \\
\hline Adenokarsinom & $14(\% 36,8)$ \\
Skuamoz hücreli karsinom & $13(\% 34,2)$ \\
Küçük hücreli karsinom & $5(\% 13,2)$ \\
Karsinoid tümör & $4(\% 10,5)$ \\
Küçük hücreli & dişı \\
(sınıflandırılamayan) & $2(\% 5,3)$ \\
\hline Benign & $16(\% 29,6)$ \\
\hline Nekrotizan granülomatöz inflamasyon & $6(\% 37,5)$ \\
Kronik nonspesifik inflamasyon & $7(\% 43,8)$ \\
Hamartom & $2(\% 12,5)$ \\
Aspergilloz & $1(\% 6,2)$ \\
\hline
\end{tabular}

\section{Malign Lezyon Saptanan Hastalar}

Toplam 38 hastada (7 K, 31 E) malign lezyon mevcuttu. Histopatolojik olarak en sik tanı adenokarsinom olup 14 hastada $(\% 36,8)$ tespit edildi. Skuamoz hücreli karsinom 13 hastada (\%34,2), küçük hücreli karsinom 5 hastada $(\% 13,2)$, karsinoid tümör 4 hastada $(\% 10,5)$ ve sinıflandırılamayan küçük hücreli dışı karsinom 2 hastada $(\% 5,3)$ saptandı. Karsinoid tümör saptanan 3/4 hastada tipik karsinoid tümör ve 1 hastada atipik karsinoid tümör bulgusu mevcuttu. Lezyonların ortalama ( \pm ss) ve ortanca (min-maks) aksiyel çapı sırasıyla $23 \pm 6$ $\mathrm{mm}$ ve $19 \mathrm{~mm}(11-30 \mathrm{~mm})$; ortalama $( \pm \mathrm{ss})$ ve ortanca (min-maks) maksSTD değeri sırasıyla $8,98 \pm 6,4$ ve $7,53(1,02-25,14)$ olarak belirlendi. Maksimum STD değeri $\geq 2,5$ olan 36 hasta $(\% 94,7) ;<2,5$ olan 2 hasta $(\% 5,3)$ mevcuttu.
MaksSTD eșik değerinin altında tutulum izlenen hastaların birisinde skuamöz hücreli karsinom ve diğerinde karsinoid tümör tespit edildi. Tipik karsinoid tümör saptanan hastaya ait F-18 FDG $\mathrm{PET} / \mathrm{BT}$ görüntüleri resim 1'de sunulmuştur.
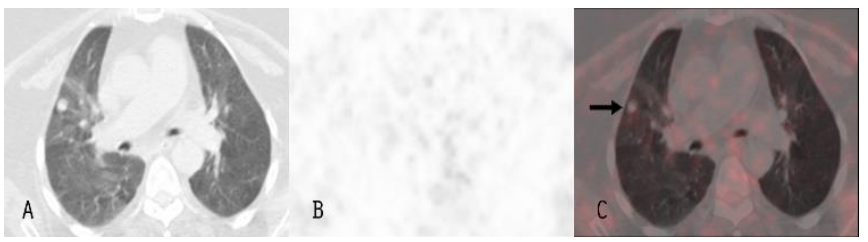

Resim 1: 65 yaşındaki erkek hastaya ait FDG PET/BT görüntülerinin BT (A), PET (B) ve füzyon (C) görüntülerinde să akciğerde 10x9 mm boyutlu nodüler lezyon izlenmektedir. Lezyonun maksimum standardize tutulum değeri 1,02'dir. Histopatolojik tanı tipik karsinoid tümör ile uyumludur.

\section{Benign Lezyon Saptanan Hastalar}

Histopatolojik olarak benign lezyon tespit edilen toplam 16 hastanın 7'sinde $(\% 43,8)$ kronik nonspesifik inflamasyon,6'sinda $(\% 37,5)$ nekrotizan granülomatöz inflamasyon izlenirken, 3 hastada (\% 11,5) hamartom, bir hastada ise $(\% 6,1)$ aspergilloz saptand. Lezyonların ortalama ( \pm ss) ve ortanca (minmaks) aksiyel çapı sırasıyla $23 \pm 7 \mathrm{~mm}$ ve 23,5 $\mathrm{mm}(9-30 \mathrm{~mm})$; ortalama $( \pm \mathrm{ss})$ ve ortanca (minmaks) maksSTD değeri sırasıyla $3,69 \pm 2,86$ ve 2,71 (1,06-12,21) olarak belirlendi.

Benign histopatolojik tanı alan 8/16 hastada $(\% 50,0)$ maksSTD değeri $\geq 2,5$ olarak belirlendi. $\mathrm{Bu}$ hastaların 4' ünde kronik nonspesifik inflamasyon, 3'ünde nekrotizan granülomatöz inflamasyon ve 1'inde aspergilloz mevcuttu. Aspergilloz saptanan hastaya ait PET/BT görüntüleri resim 2'de sunulmuştur.
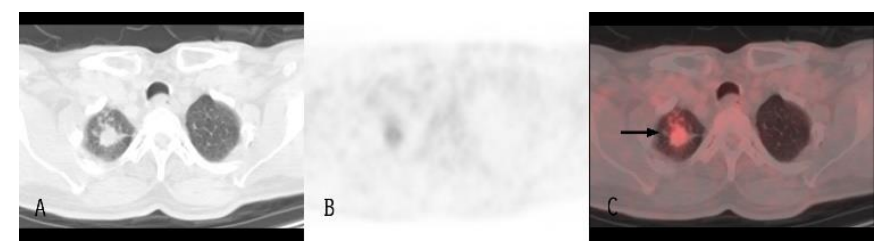

Resim 2: 74 yaşındaki erkek hastaya ait FDG PET/BT görüntülerinin BT (A), PET (B) ve füzyon (C) görüntülerinde sağ akciğer apikal segmentte $21 \times 20 \mathrm{~mm}$ boyutlu nodüler lezyon izlenmektedir. Lezyonun maksimum standardize tutulum değeri 3,83 olup, wedge rezeksiyon ile elde edilen materyalin histopatolojik tanısı aspergilloma ile uyumludur. 
Benign ve malign lezyonların medyan aksiyel çapları arasında istatistiksel olarak anlamlı fark izlenmezken, maksSTD değerleri malign lezyonlarda anlamlı düzeyde yüksek bulundu $(\mathrm{p}=0,001)$ (Tablo II).

Tablo II: Benign ve malign lezyonların ortalama ( \pm ss) maksSTD değerleri ve maksimum aksiyel çapları.

\begin{tabular}{|lccc|}
\hline & Malign & Benign & $\mathbf{P}^{*}$ \\
\hline Maks STD & $8,98(6,4)$ & $3,69(2,86)$ & 0,001 \\
$\begin{array}{c}\text { Lezyon Aksiyel } \\
\text { Çap } \mathbf{1}^{\mathbf{a}}\end{array}$ & $23(6)$ & $23(7)$ & $>0,05$ \\
\hline
\end{tabular}

* Mann Whitney $U$ testi ile elde edilen $p$ değeri

a $\mathrm{mm}$

MaksSTD için eşik değerin 2,5 olarak kabul edilmesi durumunda malign lezyonların tespitinde F-18 FDG PET-BT tetkikinin duyarlılığı \%95,1 ve özgüllüğ̈̈ \%50,0 olarak belirlenmiş olup, hasta sayıları tablo III' de sunulmuştur.

Tablo III: MaksSTD için 2,5 eşik değer olarak kabul edildiğinde malign ve benign lezyon lehine bulgu saptanan hasta sayıları.

\begin{tabular}{|cccc|}
\hline $\begin{array}{c}\text { Histopatolojik } \\
\text { Tanı }(\mathrm{n})\end{array}$ & $\begin{array}{c}\text { maksSTD } \\
\geq 2,5\end{array}$ & $\begin{array}{c}\text { maksSTD } \\
<2,5\end{array}$ & \\
\hline Malign $(\mathrm{n}=38)$ & $36(\% 94,7)$ & $2(\% 5,3)$ & \\
Benign (n=16) & $8(\% 50,0)$ & $8(\% 50,0)$ & \\
\hline
\end{tabular}

*Ki kare testi ile elde edilen $p$ değeri

\section{TARTIŞMA}

Çalışmamızda SPN karakterizasyonu açısından F-18 FDG PET/BT tetkikinin tanısal değerinin araştırılması amacı ile histopatolojik tanıları mevcut olan toplam 54 hastaya ait bulgular değerlendirilmiştir. Çalışmaya dahil edilen hastaların 38' inde malign $(\% 70,4)$ ve $16^{\prime}$ sinda benign $(\% 29,6)$ histopatolojik bulgular tespit edilmiştir. Ortalama maksSTD değeri malign lezyonlarda $8,98 \pm 6,4$ ve benign lezyonlarda $3,69 \pm 2,86$ olarak tespit edilmiş olup, literatür ile uyumlu şekilde malign lezyonlarda anlamlı düzeyde yüksek bulunmuştur ${ }^{3}$. MaksSTD için eşik değerin 2,5 olarak kabul edilmesi durumunda malign lezyonların tespitinde F-18 FDG PET-BT tetkikinin duyarlılığı \%95,1 ve özgüllügü \%50,0 olarak belirlenmiştir. Gould ve arkadaşlarının yaptığ tetkikin duyarlılığı \%96,8 ve özgüllüğü \%77,8 olarak rapor edilmiştir ${ }^{4}$. Başka çalışmalarda da benzer şekilde yüksek duyarlılık ve özgüllük oranları bildirilmiştir ${ }^{5-7}$. Literatür ile uyumlu şekilde, çalışmamızda hastaların büyük kısmında malignite tespiti açısından yüksek maksSTD değerlerinde tetkikin duyarlılığının yüksek olduğu görülmektedir. Karsinoid tümör ve skuamöz hücreli karsinom saptanan birer hastada maksSTD değerleri 2,5'un altında olup, yanlış negatif bulgu vermiştir. Adenokarsinom ve bronkoalveoler karsinom bașta olmak üzere düşük grade'li lezyonlarda yanlış negatif F-18 FDG PET/BT bulgularına rastlanmaktadır ${ }^{8}$. Skuamöz hücreli karsinomlarda ise bu durum daha nadir olarak karşımıza çıkmakla birlikte literatürde benzer vakalar bildirilmiștir ${ }^{9}$. Genel olarak çapı F-18 FDG PET/BT' nin tanısal değerinin $1 \mathrm{~cm}$ 'nin üzerindeki nodüllerde yüksek olduğu, buna karşıllk 1 cm'nin altındaki nodüllerde ise sınırlı olduğu bilinmektedir ${ }^{4}$. Milimetrik ve subsantimetrik boyutlu nodülü olan hastalar mevcut çalışmaya dahil edilmemiştir. $\mathrm{Bu}$ durumun çalışmamızda tetkikin duyarlılığının yüksek olarak belirlenmesinin nedeni olabileceği düşünülmektedir.

Çalışmadan elde edilen verilere göre, F-18 FDG PET/BT tetkikinin malignite tespitindeki duyarlılık oranının yüksek olmasına karşılık özgüllügünün \%50,0 düzeyinde olduğu ve literatürün altında kaldığı dikkati çekmektedir. En sık tüberküloz olmak üzere aktif granülomatöz enfeksiyonlardaki artmış F-18 FDG akümülasyonunun malignite ayırıcı tanısında yanlış pozitif sonuçlara neden olduğu bilinmektedir ${ }^{5}$. Çalışmamızda da en sık yanlış pozitif bulgu nedenleri kronik nonspesifik enfeksiyon ve nekrotizan granülomatöz 
inflamasyonlardır. Bölgemizde de halen yaygın olarak izlenen tüberküloz enfeksiyonunun özgüllüğün düșük olması ile ilişkili olduğu düşünülmektedir. Tüberküloz enfeksiyonunun yüksek olarak izlendiği bölgelerde de benzer sonuçlar bildirilmesi bu düşüncemizi desteklemektedir ${ }^{10}$. Soliter pulmoner nodül ayırıcı tanısında malignite açısından yanlış pozitif vaka sayısının azaltılması için F-18 FDG PET/BT sonuçlarının değerlendirilmesinde bu durumun özellikle dikkate alınması gerekmektedir.

Soliter pulmoner nodüllerin değerlendirilmesinde $\quad$ F-18 FDG PET/BT tetkikinin gerek duyarlılığını, gerekse özgüllüğünü artırmak üzere teknik açıdan bazı modifikasyonlar denenmiştir. Dual faz görüntüleme metodu üzerinde en fazla çalışılan teknik olmuştur. Dual faz metodu, F-18 FDG akümülasyonun malign lezyonlarda zaman içinde artışı ve benign lezyonlarda sabit kalması veya azalması ile ilișkilendirilmiş bir yöntem olup, lezyon ayırıcı tanısına katkısı konusunda farklı görüşler mevcuttur. Matthies ve arkadaşları bu metod ile malign lezyon tespitinde duyarlılığın \%20 oranında arttığını rapor etmişlerdir ${ }^{11}$. Buna karşılık iki meta analizde dual faz metodunun malign lezyonların ayırıcı tanısında ek katkı sağlamadığı bildirilmektedir ${ }^{12,13}$. Çalıșmalarda özellikle tüberküloz enfeksiyonunun yaygın olarak izlendiği bölgelerde geç dönemdeki maksSTD artışının malign lezyon ayırıcı tanısına katkısı olmadığı, granülomatöz enfeksiyonlarda da benzer bulgular izlenebileceği belirtilmektedir ${ }^{14}$. Çalışmaya dahil edilen hasta grubunda rutin görüntülemede dual faz protokolü uygulanmadığından bu konuda bulgu elde edilememiştir.

Yüksek çözünürlüklü bilgisayarlı tomografi sistemlerinin kullanımın yaygınlaşması ile birlikte soliter pulmoner nodül tanısında artış olduğu bilinmektedir. Rezeksiyon materyallerinden elde edilen malignite oranlarında da benzer șekilde artış izlenmiș olup,\%30-40 düzeyinden \%60-80'lere yükselmiştir15-17. Çalışmada hastalarımızın \%70,4'ünde nodüllerin histopatolojik tanısı malignite ile uyumlu olup, literatürde belirtilen oranların üst sınırına yakın düzeydedir. Genel olarak malignite kuşkusu yüksek olan nodüllerin rezeke edilmesinin literatürdeki yüksek oranlara neden olduğu düşünülmektedir. Çalışmada elde ettiğimiz yüksek malignite oranı da bu durum ile ilișkili olabilir.

Çalışmamızda benign ve malign lezyonların medyan aksiyel çapları arasında istatistiksel olarak anlamlı fark izlenmemiştir. Literatürde bu konuda farklı görüşler bulunmaktadır. Yang ve arkadaşları, SPN çapı ile malignite arasında pozitif korelasyon olduğunu rapor etmişlerdir ${ }^{18}$. Buna karşılık, malignite ile lezyon çapları arasında anlamlı ilişki olmadığını bildiren çalışmalar da mevcuttur ${ }^{19,20}$. Davies ve arkadaşları 150 hasta üzerinde yaptıkları çalışmada benign ve malign lezyon aksiyel çaplarını sırasıyla $17,7 \mathrm{~mm}$ ve $20,6 \mathrm{~mm}$ olarak rapor etmişler ve lezyon çapı ile malignite riski arasında anlamlı ilişki olmadığını bildirmişlerdir ${ }^{21}$. Çalışmamızda da benign ve malign lezyonların aksiyel çapları birbirine oldukça yakın olup, anlamlı fark saptanmamıştır.

Çalışmaya dahil edilen hasta sayısının düşük olması çalışmamızın kısıtlılığı olarak düşünülmektedir. $\mathrm{Bu}$ nedenle farklı nodül boyutlarında ve farklı histopatolojik tipteki lezyonlarda PET/BT yönteminin lezyon karakterizasyonuna katkısı hakkında yorum yapılamamıștır. Daha geniş hasta serileri üzerinde yapılan çalışmalarda bu konuda literatüre katkı sağlanabileceği düşünülmektedir.

Çalışmadan elde edilen veriler, F-18 FDG PET/BT' nin aksiyel çapı 1 cm'den büyük soliter pulmoner nodüllerde benign-malign lezyon ayrımı için yüksek duyarlılığa sahip bir 
görüntüleme yöntemi olduğu yönündedir. Bununla birlikte düşük grade'li bazı malign lezyonlarda tetkikin yanlış negatif sonuç verebileceği göz önünde bulundurulmalıdır. En sık yanlış pozitif bulgu veren durumlar kronik inflamasyon ve granülomatöz lezyonlar olup, ülkemizde halen sıklıkla karşılaşılması nedeni ile özellikle tüberküloz enfeksiyonu açısından hastaların klinik bulgularına özellikle dikkat edilmesi gerekmektedir.

Etik Kurul Kararı: Çalışma Ondokuz Mayıs Üniversitesi Klinik Araştırmalar Etik Kurulu tarafından onaylandı.

Çıkar Çatışması Beyanı: Yazarlar çıkar çatışması olmadığını bildirmişlerdir.

Finansal Destek: Bu çalışma her hangi bir fon tarafından desteklenmemiştir.

Declaration of Conflicting Interests: The authors declare that they have no conflict of interest.

Financial Disclosure: No financial support was received.

\section{KAYNAKLAR}

1. Czernin J, Allen-Auerbach M, Nathanson D, Herrmann K. PET/CT in Oncology: Current Status and Perspectives. Curr Radiol Rep 2013; 1: 177-90.

2. Yankelevitz DF, Henscke CI.Does 2 years stability imply that pulmonary nodüle are benign?Am J Roentgenol 1997; 168:325-8.

3. Hou S, Lin X, Wang S, et al. Combination of positron emission tomography/computed tomography and chest thin-layer highresolution computed tomography for evaluation of pulmonary nodules: Correlation with imaging features, maximum standardized uptake value, and pathology. Medicine (Baltimore) 2018;97(31):e11640. doi: 10.1097/MD.0000000000011640.

4. Gould MK, Maclean CC, Kuschner WG, Rydzak CE, Owens DK. Accuracy of positron emission tomography for diagnosis of pulmonary nodules and mass lesions: a meta-analysis. JAMA 2001; 285: 914-24.

5. Li Y, Su M, Li F, Kuang A, Tian R. The value of ${ }^{18} \mathrm{~F}$-FDG-PET/CT in the differential diagnosis of solitary pulmonary nodules in areas with a high incidence of tuberculosis. Ann Nucl Med 2011; 25: 804-11.

6. Jeong SY, Lee KS, Shin KM, et al. Efficacy of PET/CT in the characterization of solid or partly solid solitary pulmonary nodules. Lung Cancer 2008; 61: 186-94.

7. Jeong YJ, Yi CA, Lee KS. Solitary pulmonary nodules: detection, characterization, and guidance for further diagnostic workup and treatment. AJR Am J Roentgenol 2007; 188: 5768.

8. Kim BT, Kim Y, Lee KS, et al. Localized form of bronchioloalveolar carcinoma: FDG PET findings. AJR Am J Roentgenol 1998; 170: 935 9.

9. Cheran SK, Nielsen ND, Patz EF. FalseNegative Findings for Primary Lung Tumors on FDG Positron Emission Tomography: Staging and Prognostic Implications. AJR Am J Roentgenol 2004; 182: 1129-32.

10. Fletcher JW, Kymes SM, Gould M, et al. A comparison of the diagnostic accuracy of $18 \mathrm{~F}$ FDG PET and CT in the characterization of solitary pulmonary nodules. J Nucl Med 2008; 49: 179-85.

11. Matthies A, Hickeson M, Cuchiara A, Alavi A. Dual time point 18F-FDG PET for the evaluation of pulmonary nodules. J Nucl Med 2002; 43: 871-5.

12. Barger RL Jr., Nandalur KR. Diagnostic performance of dual-time 18F-FDG PET in the diagnosis of pulmonary nodules: A metaanalysis. Acad Radiol 2012; 19: 153-8.

13. Zhang L, Wang Y, Lei J, Tian J, Zhai Y. Dual time point 18FDG-PET/CT versus single time 
point 18FDG-PET/CT for the differential diagnosis of pulmonary nodules: A metaanalysis. Acta Radiol 2013; 54: 770-7.

14. Sathekge MM, Maes A, Pottel H, Stoltz A, van de Wiele C. Dual time-point FDG PET-CT for differentiating benign from malignant solitary pulmonary nodules in a TB endemic area. S Afr Med J 2010;100:598-601.

15. Chang CY, Tzao C, Lee SC, et al. Incremental value of integrated FDG-PET/CT in evaluating indeterminate solitary pulmonary nodule for malignancy. Mol Imaging Biol 2010; 12: 204-9.

16. Ooi GC, Khong PL, Yau YY. Advances in imaging of the solitary pulmonary nodule. Hong Kong Med J 2004; 10: 107-16.

17. Erasmus JJ, Connolly JE, McAdams HP, Roggli VL. Solitary pulmonary nodules: Part I. orphologic evaluation for differentiation of benign and malignant lesions. Radiographics 2000; 20: 43-58.
18. Yang D, Li Y, Liu J, et al. Study on solitary pulmonary nodules: correlation between diameter and clinical manifestation and pathological features. Zhongguo Fei Ai Za Zhi 2010; 13: 607-11.

19. Nguyen NC, Kaushik A, Wolverson MK, Osman MM. Is there a common SUV threshold in oncological FDG PET/CT, at least for some common indications? A retrospective study. Acta Oncologica 2011; 50: 670-77.

20. Orlacchio A, Schillaci O, Antonelli L, et al. Solitary pulmonary nodules: morphological and metabolic characterisation by FDG-PET-MDCT. Radiol med 2007; 112: 157-73.

21. Davies B, Ghosh S, Hopkinson D, Vaughan R, Rocco G. Solitary pulmonary nodules: pathological outcome of 150 consecutively resected lesions. Interact Cardiovasc Thorac Surg 2005; 4: 18-20. 